\title{
PERAMALAN HARGA EMAS DENGAN MODEL GENERALIZED AUTOREGRESSIVE CONDITIONAL HETEROSCEDASTICITY (GARCH)
}

\section{GOLD PRICE FORECASTING WITH GENERALIZED AUTOREGRESSIVE CONDITIONAL HETEROSCEDASTICITY (GARCH) MODEL}

\author{
M. Al Haris* dan Prizka Rismawati Arum \\ Dosen Program Studi Statistika, Universitas Muhammadiyah Semarang \\ Jl. Kedungmundu No.18, Kec. Tembalang, Kota Semarang, Jawa Tengah \\ *alharis@unimus.ac.id
}

\begin{abstract}
Gold was the one of the long-term investment commodities that were considered as the safe heaven for investors. The gold price was strongly influenced by global socioeconomic that causing fluctuations in price changes. The Fluctuations of gold price would be causing the denying of homogeneous variance assumption (heteroscedasticity). The purpous of This study was to apply Generalized Autoregressive Conditional Heteroscedasticity (GARCH) to model the fluctuations of gold prices. GARCH was the development of Autoregressive Conditional Heteroscedasticity (ARCH) model which was used to model the heterogeneous variance of the mean model. The data used in this study was the daily gold price data from May 5 th 2015 to May 27 $7^{\text {th }}, 2020$. The results of this study showing the best model based on the smallest AIC value of -6.8788 was ARIMA $(1,1,0)$ GARCH $(1,1)$.
\end{abstract}

Keywords: AIC, ARCH, GARCH, gold price.

\begin{abstract}
ABSTRAK
Emas merupakan salah satu komoditas investasi jangka panjang yang dipandang aman bagi para investor. Harga emas sangat dipengaruhi oleh kondisi sosial ekonomi global yang mengakibatkan terjadinya perubahan harga secara fluktuatif. Fluktuasi harga emas akan berdampak pada pelanggaran asumsi kehomogenan ragam (heteroskedastisitas). Penelitian ini menerapkan Generalized Autoregressive Conditional Heteroscedasticity (GARCH) untuk memodelkan fluktuasi harga emas. GARCH merupakan pengembangan dari model Autoregressive Conditional Heteroscedasticity (ARCH) yang digunakan untuk memodelkan ragam sisaan pada model rataan yang tidak homogen. Data yang digunakan pada penelitian ini adalah data harian harga emas dunia periode 5 Mei 2015 hingga 27 Mei 2020. Hasil penelitian menunjukkan model terbaik berdasarkan nilai AIC terkecil -6.8788 adalah ARIMA $(1,1,0)$ GARCH $(1,1)$.
\end{abstract}

Kata kunci: AIC, ARCH, GARCH, harga emas.

\section{PENDAHULUAN}

Investasi emas merupakan salah satu jenis investasi yang banyak diminati masyarakat. Komoditi emas dipandang oleh sebagian besar investor sebagai alat investasi aman dan sudah dilakukan sejak dulu. Di samping itu, emas juga digunakan sebagai standar keuangan atau ekonomi, cadangan devisa dan alat pembayaran yang paling utama di beberapa negara (Mahena, et. al., 2015). Emas pada hakikatnya 
berfungsi untuk menahan inflasi. Sejak tahun 1998 hingga tahun 2010, harga emas mengalami kenaikan secara kumulatif jauh di atas perubahan kumulatif inflasi. Selama terjadi krisis finansial 2008-2009, banyak harga komoditi mengalami penurunan kurang lebih 40\%, tetapi harga emas global cenderung naik rata-rata 6\% (Tripathy, 2017). Proctor (2012) dalam Anita (2015) menyatakan bahwa dalam kondisi yang tidak stabil, langkah terbaik untuk seorang investor adalah memiliki beberapa jaminan dalam aset fisik dan aset likuid yang dapat dilikuidasi sewaktu-waktu. Investor menginvestasikan asetnya dalam bentuk emas untuk mengurangi kerugian, sehingga peramalan harga emas menjadi permasalahan yang sangan penting di bidang ekonomi keuangan (Tripathy, 2017).

Peramalan merupakan proses pendugaan secara sistematik tentang sesuatu di masa yang akan datang berdasarkan informasi masa lalu dan masa sekarang. Harapan dari proses peramalan adalah menghasilkan selisih yang sekecil mungkin antara hasil peramalan dengan apa yang terjadi di masa yang akan datang. Peramalan membutuhkan data deret waktu yang cukup panjang dan informasi data yang cukup banyak untuk mendapatkan hasil ramalan yang baik. Salah satu metode yang sering digunakan untuk peramalan adalah Autoregressive Integrated Moving Average (ARIMA). Model ARIMA memiliki fleksibilitas yang tinggi dalam menganalisis berbagai data deret waktu dan nilai ramalan yang dihasilkan lebih akurat (Montgomery, et. al., 2008).

Model ARIMA memiliki asumsi yang harus dipenuhi, diantaranya sisaan menyebar normal, sisaan saling bebas dan ragam sisaan homogen. Akan tetapi, pada data yang memiliki fluktuasi yang tinggi seperti data harga emas harian, model ARIMA menghasilkan ragam sisaan yang tidak homogen. Ketidakhomogenan ragam sisaan akan menyebabkan pendugaan parameter pada model menjadi tidak valid (Untari, et. al., 2009). Metode yang dapat digunakan untuk mengatasi ketidakhomogenan ragam sisaan yaitu melalui pemodelan ragam sisaan yang dikenal dengan model Autoregressive Conditional Heteroscedasticity (ARCH) dan Generalized Autoregressive Conditional Heteroscedasticity (GARCH). Menurut Ruppert dan Matteson (2011) model ARCHGARCH dapat memperhitungkan tingkat volatilitas tinggi yang tidak dapat dilakukan oleh model ARIMA. Sehingga pada penelitian ini akan dilakukan pemodelan ARCHGARCH serta melakukan peramalan harga komoditas emas dengan data harian dari periode 5 Mei 2015 sampai 24 Mei 2020. 


\section{METODOLOGI}

\subsection{Analisis Runtun Waktu}

Data runtun waktu merupakan serangkaian pengamatan yang diukur pada interval waktu yang sama. Dasar pemikirannya adalah data pada pengamatan ke- $t\left(\mathrm{Z}_{\mathrm{t}}\right)$ berpengaruh pada satu atau beberapa pengamatan sebelumnya $\left(\mathrm{Z}_{\mathrm{t}-\mathrm{k}}\right)$. Analisis data runtun waktu dilakukan untuk menentukan pola sistematis sehingga dapat disusun suatu model matematis yang dapat menjelaskan perilaku masa lalu dari deret tersebut dan dimanfaatkan untuk menduga nilai data pada periode kedepan (forecasting) (Wei, 2006).

\subsection{Uji Stasioneritas}

Stasioneritas data merupakan hal yang sangat penting dalam pemodelan data runtun waktu. Data deret waktu yang stasioner berarti memiliki rataan dan ragam yang konstan (Cryer dan Chan, 2008). Ketidakstasioneran data dalam rataan dilihat dengan menggunakan Uji ADF (Augmented Dickey Fuller). Model yang akan diuji adalah:

$$
\Delta Z_{t}=\omega Z_{t-1}+\emptyset_{1} \Delta Z_{t-1}+\cdots+\emptyset_{k} \Delta Z_{t-k+1}+e_{t}
$$

dengan $Y_{t}$ merupakan data runtun waktu pada periode ke $t$ dan $k$ menunjukkan ordo lag dari proses autoregresi. Hipotesis yang diuji sebagai berikut:

$H_{0}: \omega=0$ (Terdapat akar unit/data belum stasioner terhadap rataan)

$H_{1}: \omega<0$ (Tidak terdapat akar unit/data stasioner terhadap rataan)

statistik uji yang digunakan

$$
D F=\frac{\widehat{\mathrm{u}}}{S E(\widehat{\omega})}
$$

dengan $\widehat{\omega}$ merupakan penduga dari koefisien $\omega$ dan $S E \widehat{\omega}$ adalah nilai standard error dari $\widehat{\omega}$. Kriteria pengujian adalah jika statistik ADF lebih kecil dibandingkan nilai kritisnya, maka hipotesis nol ditolak. Jika data terbukti tidak stasioner terhadap rataan, maka diperlukan differencing (Cryer dan Chan, 2008).

Proses stasioneritas dalam ragam dapat di lakukan dengan transformasi BoxCox. Transformasi dilakukan dengan memangkatkan data runtun waktu dengan suatu nilai parameter transformasi $(\lambda)$. Data dikatakan stasioner terhadap ragam jika nilai selang kepercayaan $\lambda$ memuat nilai 1 (Trianto, 2015).

\subsection{Autoregressive Integrate Moving Average (ARIMA)}

Model ARIMA pertama kali dikembangkan oleh George Box dan Gwilyn Jenskin. Model ini merupakan gabungan antara model Autoregressive (AR) dan Moving 
Average (MA) serta memperoleh pembedaan (differencing) sebanyak $d$ kali. Bentuk umum model ARIMA $(p, d, q)$ adalah sebagai berikut:

$$
\phi_{p}(B)(1-B)^{d} Z_{t}=\theta_{q}(B) e_{t}
$$

dengan $\phi_{p}(B)=\left(\left(1-\phi_{1} B-\cdots-\phi_{1} B^{p}\right)\right.$ dan $\theta_{q}(B)=\left(\left(1-\theta_{1} B-\cdots-\theta_{1} B^{q}\right)\right.$. Model ARIMA memiliki asumsi sisaan saling bebas serta menyebar normal dengan nilai tengah nol dan ragam homogen. Identifikasi model ARIMA didasarkan pada analisis terhadap plot Autocorrelation function (ACF) dan plot Partial Autocorrelation function (PACF) (Montgomery et. al., 2008).

\subsection{Pemerisaan Asumsi Sisaan}

Pemeriksaan kebebasan pada sisaan dilakukan menggunakan uji Ljung-Box dengan hipotesis sebagai berikut (Enders, 2004):

$H_{0}: r_{1}=r_{2}=\cdots=r_{k}=0$ (tidak terdapat autokorelasi sisaan disemua lag $k$ )

$H_{1}$ : terdapat satu $r_{k} \neq 0$ (terdapat korelasi sisaan antar lag $k$ )

statistik uji yang digunakan

$$
Q_{L B}=n(n+2) \sum_{j=1}^{k} \frac{r_{j}^{2}}{n-k}
$$

dengan $r_{j}^{2}$ merupakan autokorelasi sisaan ke-j, $n$ adalah banyaknya pengamatan dan $k$ adalah lag maksimum yang diingikan. Statistik uji Ljung-Box menyebar Khi-kuadrat dengan derajat bebas $k-p-q$ dengan $p$ dan $q$ merupakan ordo pada model. Nilai $Q_{L B}>$ $\chi_{k-p-q}^{2}(\alpha)$ menunjukkan penolakan $H_{0}$.

Pemeriksaan kenormalan sisaan pada data deret waktu dapat dilakukan dengan uji Kolmogorov-Smirnov (Montgomery, et. al., 2008). Hipotesis yag digunakan pada pengujian ini adalah:

$$
\begin{array}{ll}
H_{0}: F\left(a_{t}\right)=F_{0}\left(a_{t}\right) & \text { (sisaan menyebar normal) } \\
H_{1}: F\left(a_{t}\right) \neq F_{0}\left(a_{t}\right) & \text { (sisaan tidak menyebar normal) }
\end{array}
$$

statistik uji Kolmogorov-Smirnov:

$$
D=\sup \left|S\left(a_{t}\right)-F_{0}\left(a_{t}\right)\right|
$$

kriteria pengujian adalah jika $D>F_{1-\alpha / 2}$ atau $p$-value $<\alpha$, maka $H_{0}$ ditolak.

\subsection{Uji Lagrange Multiplier}

Uji Lagrange Multiplier (LM) digunakan untuk menguji kehomogenan ragam sisaan yang mendeteksi adanya proes ARCH-GARCH. Sisaan yang diperoleh dari 
model ARIMA dikuadratkan. Kemudian dilanjutkan dengan meregresikan kuadrat sisaan dengan menggunakan konstanta sampai lag ke $q$, model:

$$
e_{t}^{2}=\beta_{0}+\beta_{1} e_{t-1}^{2}+\cdots+\beta_{p} e_{t-q}^{2}+v_{t}
$$

Jika nilai dugaan $\beta_{1}$ sampai dengan $\beta_{p}$ bernilai nol, maka dapat disimpulkan bahwa $e_{t}$ tidak memiliki autokorelasi yang nyata atau dengan kata lain tidak terdapat pengaruh ARCH-GARCH. Sehingga hipotesis yang dibangun adalah:

$$
H_{0}: \beta_{1}=\beta_{2}=\cdots=\beta_{q}=0 \text { (tidak terdapat pengaruh ARCH-GARCH ) }
$$

$H_{1}:$ minimal ada satu $\beta_{i} \neq 0$, untuk $i=1,2, \ldots, q$ (terdapat pengaruh

\section{ARCH-GARCH)}

satistik uji yang digunakan adalah:

$$
L M=n R^{2}
$$

dengan $n$ merupakan jumlah amatan dan $R^{2}$ koefisien determinasi dari model. Statistik uji LM mengikuti sebaran khi-kuadrat dengan derajat bebas q yang merupakan ordo dari ARCH. Hipotesis nol ditolak jika statistik uji LM > nilai tabel $\div_{(q)}^{2}$ dengan taraf nyata tertentu $(\alpha)$ atau $p$-value lebih kecil dari $\alpha$ (Enders, 2004).

\subsection{Autoregressive Conditional Heteroscedasticity (ARCH)}

Pemodelan dengan ARIMA sering dijumpai pelanggaran terhadap kehomogenan ragam sisaan (heteroskedastisitas) yang mengakibatkan penggunaan model ARIMA kurang tepat. Engle dalam Pindyck et. al. (1998) menyatakan bahwa volatilitas ragam sisaan terjadi karena ragam sisaan tidak hanya merupakan fungsi dari peubah bebas, tetapi juga tergantung dari seberapa besar sisaan dimasa lalu. Oleh karena itu, Engle mengusulkan suatu model yang disebut Autoregressive Conditional Heteroscedasticity $(\mathrm{ARCH})$. Persamaan ragam sisaan dalam model ARCH $(p)$ dapat dinyatakan dalam bentuk persamaan sebagai berikut:

$$
\sigma_{t}^{2}=\beta_{0}+\beta_{1} e_{t-1}^{2}+\beta_{2} e_{t-2}^{2}+\cdots+\beta_{p} e_{t-p}^{2}
$$

$\sigma_{t}^{2}$ merupakan ragam sisaan pada waktu ke $t, e_{t-q}^{2}$ adalah kuadrat sisaan pada waktu ke $t-p, \beta_{0}>0, \beta_{1}, \beta_{2}, \ldots, \beta_{p} \geq 0$ yang merupakan parameter model ARCH (Enders, 2004).

\subsection{Generalized Autoregressive Conditional Heteoscedasticity (GARCH)}

Model ARCH kurang efektif untuk mengatasi heteroskedastisitas jika lag yang terbentuk besar (Enders, 2004), untuk itu model ARCH dikembangkan menjadi model 
GARCH oleh Bollerslev (1986). Ragam sisaan $\left(\sigma_{t}^{2}\right)$ model GARCH tidak hanya dipengaruhi oleh sisaan periode sebelumnya $\left(e_{t-1}^{2}\right)$ tetapi juga dipengaruhi oleh ragam sisaan periode sebelumnya $\left(\sigma_{t-1}^{2}\right)$. Secara umum model ARCH-GARCH $(p, q)$ dinyatakan dalam persamaan berikut:

$$
\sigma_{t}^{2}=\beta_{0}+\beta_{1} e_{t-1}^{2}+\beta_{2} e_{t-2}^{2}+\cdots+\beta_{p} e_{t-p}^{2}++\gamma_{1} \sigma_{t-1}^{2}+\gamma_{2} \sigma_{t-2}^{2}+\cdots+\gamma_{q} \sigma_{t-q}^{2}
$$

dengan $\beta_{0}, \beta_{i}$ dan $\gamma_{1}$ merupakan paramter model dan $p, q$ secara berturut-turut merupakan ordo dari model ARCH-GARCH.

\subsection{Akaike's Information Criterion (AIC)}

Salah satu kriteria dalam pemilihan model terbaik adalah menggunakan Akaike's Information Criterion (AIC). Nilai AIC diperoleh dengan rumus sebagai berikut:

$$
A I C=n \ln \hat{\sigma}_{a}^{2}+2 M
$$

dengan $n$ menyatakan jumlah amatan dan $M$ adalah jumlah parameter. Kriterian pemilihan model terbaik jika model memiliki nilai AIC terkecil (Wei, 2006).

\subsection{Data dan Metode}

Data yang digunakan pada penelitian ini adalah data harian harga emas dunia yang diperoleh dari website www.quandl.com pada periode 5 Mei 2015 hingga 27 Mei 2020. Peubah yang digunakan untuk pemodelan dan peramalan adalah data harian harga emas dunia.

Tahapan yang dilakukan dalam penelitian ini adalah sebagai berikut:

1. Eksplorasi data untuk melihat kestasioneran data;

2. Melakukan uji kestasioneran data pada ragam menggunakan transformasi Box-cox dan uji stasioner dalam rataan dengan Uji ADF;

3. Mengidentifikasi model ARIMA dengan melihat plot ACF dan PACF kemudian melakukan overfitting untuk memilih model terbaik;

4. Melakukan uji kehomogenan ragam dengan uji LM. Jika asumsi kehomogenan ragam sisaan tidak terpenuhi, maka dilakukan pemodelan ragam sisaan;

5. Mengidentifikasi model ragam sisaan ARCH-GARCH kemudian melakukan overfitting;

6. Pemilihan model ARCH-GARCH terbaik dengan melihat AIC terkecil;

7. Melakukan peramalan $n$ periode kedepan berdasarkan model terbaik. 


\section{PEMBAHASAN}

\subsection{Deskripsi Data}

Plot data harian harga emas dunia dari periode 5 Mei 2015 hingga 27 Mei 2020 diperoleh data pengamatan sebanyak 1281 yang disajikan pada grafik berikut:

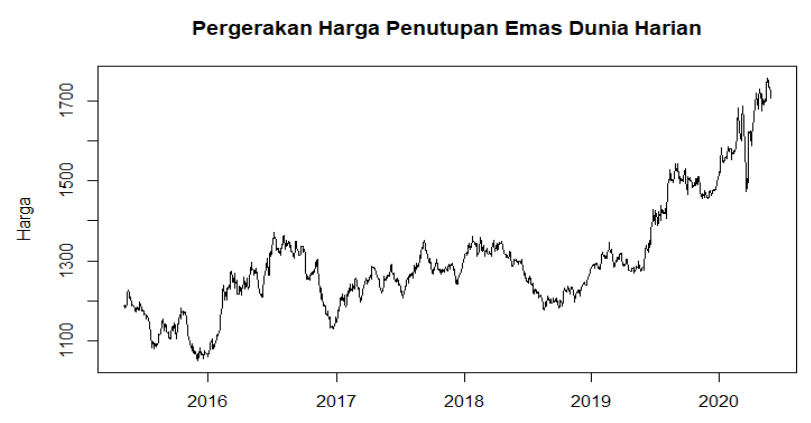

Gambar 1. Plot Data Harian Harga Emas Dunia

Gambar 1 menunjukkan terjadinya fluktuasi pada pergerakan data harian harga emas dunia. Pola fluktuasi tersebut mengindikasikan terjadinya pelanggaran asumsi kestasioneran pada data, sehingga perlu dilakukan pengujian untuk melihat kestasioneran data.

\subsection{Uji Kestasioneran Data}

Data deret waktu yang stasioner berarti memiliki rataan dan ragam yang konstan (Cryer dan Chan, 2008). Pemeriksaan kestasioneran terhadap rataan dilakukan dengan uji Augmented Dicky Fuller (ADF), sedangkan pemeriksaan kestasioneran terhadap ragam dilakukan dengan uji Box-Cox. Hasil pengujian terhadap rataan dan ragam disajikan pada tabel berikut:

Tabel 1. Pemeriksaan Kestasioneran Data

\begin{tabular}{ccc}
\hline \multirow{2}{*}{ Data } & Uji ADF & Box-Cox \\
\cline { 2 - 3 } & $p$-value & Rounded Value
\end{tabular}

Harga harian emas dunia $\quad 0,869 \quad-0,50$

Pemeriksaan kestasioneran terhadap ragam dilakukan dengan melihat nilai rounded value Box-Cox. Data dinyatakan stasioner terhadap ragam jika nilai rounded value sebesar 1 atau mendekati 1 . Hasil pengujian pada Tabel 1 menunjukkan nilai rounded value sebesar $-0,50$ sehingga dapat dinyatakan data harian harga emas dunia belum stasioner terhadap ragam. Oleh karena itu perlu dilakukan transformasi data.

Pemeriksaan kestasioneran terhadap rataan dilakukan dengan uji ADF. Hasil pengujian pada Tabel 1 menunjukkan bahwa $p$-value sebesar 0,869 lebih besar dari $\alpha$ 
yang ditentukan $(0,05)$ yang berarti tidak cukup bukti untuk menolak $H_{0}$. Hal tersebut menunjukkan data belum stasioner terhadap rataan, sehingga perlu dilakukan differencing.

Tabel 2. Pemeriksaan Kestasioneran Data setelah Transformasi dan Differencing

\begin{tabular}{ccc}
\hline \multirow{2}{*}{ Data } & Uji ADF & Box-Cox \\
\cline { 2 - 3 } & $p$-value & Rounded Value \\
\hline Harga harian emas dunia & 0,01 & 1 \\
\hline
\end{tabular}

Setelah dilakukan transformasi dan differencing pada data harian harga emas dunia menunjukkan data sudah stasioner terhadap rataan dan ragam. Tabel 2 menunjukkan rounded value Box-Cox memuat nilait 1 dan p-value uji ADF bernilai lebih kecil dari 0,05. Plot data harian harga emas dunia setelah stasioner ditunjukkan pada gambar berikut:

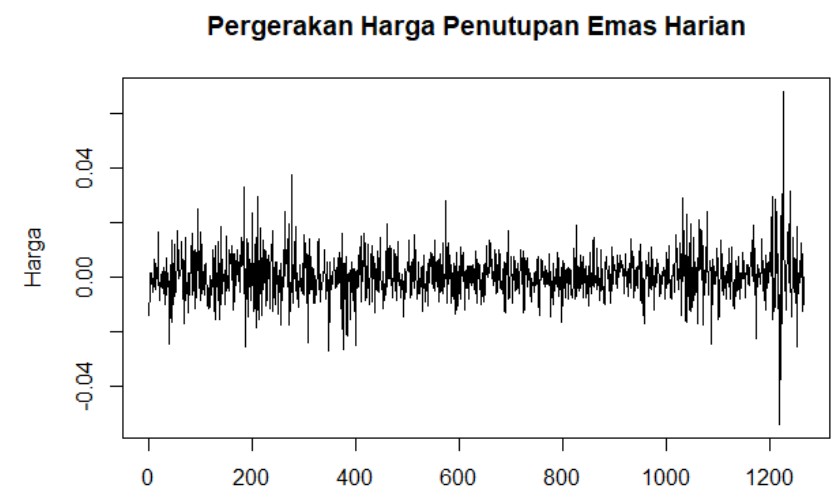

Gambar 2. Plot Data Harian Harga Emas Dunia setelah Distasionerkan

\subsection{Pemodelan ARIMA}

Tahapan awal dalam pembentukan model ARIMA adalah penentuan model tentatif dengan memperhatikan plot Autocorrelation Function (ACF) dan Partial Autocorrelation Function (PACF).
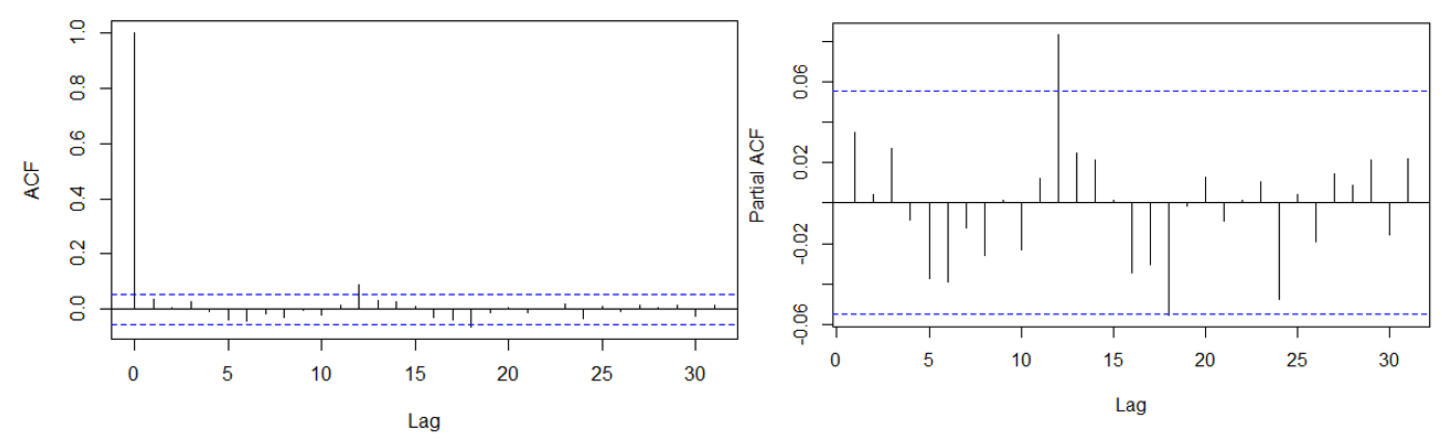

Gambar 3. Plot ACF dan PACF Data Harian Harga Emas Dunia 
Berdasarkan plot ACF dan PACF di atas, dapat dibuat model tentatif rataan mean ARIMA sebagai berikut:

Tabel 3. Model tentatif ARIMA

\begin{tabular}{clc}
\hline No & Model ARIMA & AIC \\
\hline 1 & ARIMA $(1,1,0)$ & $\mathbf{- 8 6 2 7 . 1 0 9}$ \\
\hline 2 & ARIMA $(0,1,1)$ & -8627.090 \\
\hline 3 & ARIMA $(1,1,1)$ & -8625.099 \\
\hline
\end{tabular}

Model ARIMA terbaik dipilih berdasarkan nilai AIC terkecil. Berdasarkan Tabel 3 dipilih model ARIMA $(1,1,0)$ dengan nilai AIC terkecil -8627.109.

\subsection{Pemeriksaan Efek ARCH}

Pemeriksaan adanya proses ARCH pada sisaan model ARIMA dapat dilakukan dengan uji Lagrange Multiplier (LM). Hasil pengujian adalah sebagai berikut :

Tabel 4. Pengujian Sisaan Model ARIMA

\begin{tabular}{cc}
\hline Kriteria Uji & p-value \\
\hline Ljung-Box & 0.0002387 \\
\hline Lagrange Multiplier (LM). & $2,2 \times 10^{-16}$ \\
\hline
\end{tabular}

Uji Ljung-Box digunakan untuk melihat kebebasan pada sisaan. Hasil analisis menunjukkan nilai $p$-value sebesar 0.0002387 yang lebih kecil dari $\alpha=0,05$. Hal tersebut menyebabkan $H_{0}$ ditolak, artinya terdapat korelasi antar data sisaan.

Pemeriksan ada atau tidaknya pengaruh ARCH dilakukan dengan uji LM. Berdasarkan hasil pengujian pada Tabel 4 diperoleh nilai $p$-value sebesar 2,2 $\times 10^{-16}$ yang lebih kecil dari $\alpha=0,05$. Hal tersebut menandakan $H_{0}$ ditolak yang artinya terdapat pengaruh ARCH pada sisaan, sehingga akan dilakukan analisis lebih lanjut dengan model ARCH-GARCH.

\subsection{Pemodelan ARCH-GARCH}

Identifikasi dan pengepasan model ARCH/GARCH dilakukan dengan melihat nilai AIC terkecil dan signifikansi parameternya. Berdasarkan hasil analisis yang ditunjukkan pada Tabel 5, diperoleh model ARIMA $(1,1,0)$ GARCH $(1,1)$ sebagai model terbaik dengan nilai AIC -6.8788 dan parameternya yang signifikan. Sehingga model yang terbentuk adalah :

$$
\widehat{Z}_{t}=0.000193 Z_{t-1}+0.046837 Z_{t-2}+e_{t}
$$

dengan

$$
\sigma_{t}=0.072681 e_{t-1}^{2}+0.901662 \sigma_{t-1}^{2}
$$


Tabel 5. Model Tentatif ARCH-GARCH

\begin{tabular}{cccc}
\hline No & Model & $\begin{array}{c}\text { Signifikansi } \\
\text { Parameter }\end{array}$ & AIC \\
\hline 1 & $\begin{array}{c}\text { ARIMA }(1,1,0) \\
\text { GARCH }(1,1)\end{array}$ & Signifikan & $\mathbf{- 6 . 8 7 8 8}$ \\
\hline 2 & $\begin{array}{c}\text { ARIMA }(1,1,0) \\
\text { GARCH }(2,1)\end{array}$ & Tidak signifikan & -6.8772 \\
\hline 3 & $\begin{array}{c}\text { ARIMA }(1,1,0) \\
\text { GARCH }(1,2)\end{array}$ & Tidak signifikan & -6.8773 \\
\hline 4 & $\begin{array}{c}\text { ARIMA }(1,1,0) \\
\text { GARCH }(2,2)\end{array}$ & Tidak signifikan & -6.8758 \\
\hline
\end{tabular}

\subsection{Peramalan}

Peramalan dilakukan dengan mencari nilai peramalan dari mean dan variansi dengan model terbaik yang dihasilkan. Nilai ramalan harga harian emas dunia dengan model ARIMA $(1,1,0)$ GARCH(1,1) untuk 10 periode berikutnya ditunjukkan pada gambar berikut :

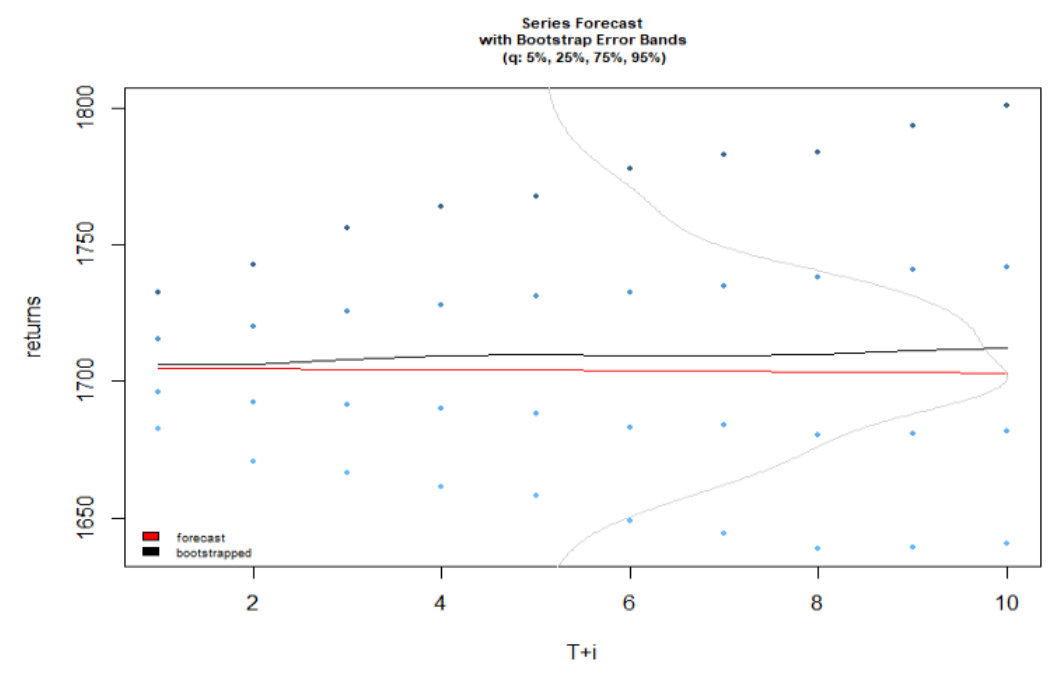

Gambar 4. Plot Prediksi Harga Harian Emas Dunia 10 Periode Kedepan

Berdasarkan plot pada Gambar 4, peramalan harga harian emas dunia selama 10 periode kedepan berada pada kisaran nilai USD\$ 1.700 dengan selang kepercayaan antara USD\$ 1.650 dan USD\$ 1.800.

\section{SIMPULAN}

Pemodelan ARCH/GARCH pada harga harian emas dunia dihasilkan model terbaik ARIMA $(1,1,0)$ GARCH $(1,1)$ dengan persamaan matematis sebagai berikut

$$
\widehat{Z}_{t}=0.000193 Z_{t-1}+0.046837 Z_{t-2}+e_{t}
$$

dengan 


$$
\sigma_{t}=0.072681 e_{t-1}^{2}+0.901662 \sigma_{t-1}^{2}
$$

Hasil peramalan harga harian emas dunia selama 10 periode kedepan dengan model terbaik menunjukkan nilai ramalan berada pada nilai USD $\$ 1.700$ dengan selang kepercayaan antara USD\$ 1.650 dan USD\$ 1.800.

\section{DAFTAR PUSTAKA}

Anita. 2015. Analisis Komparasi Investasi Logam Mulia Emas dengan Saham Perusahaan Pertambangan di Bursa Efek Indonesia 2010-2014. ESENSI : Jurnal Bisnis dan Manajemen, Vol. 5 No. 2

Bollerslev, T. 1986. Generalized Autoregressive Conditional Heteroscedasticity. Journal of Econometrics. 31:307-327

Cryer, J. D. and Chan, K. S. 2008. Time Series Analysis With Applications in R. New York: Spring Street

Enders, W. 2004. Applied Econometric Time Series, $2^{\text {rd }}$ Ed. New York: John Wiley \& Sons

Mahena, Y., Rusli, M. dan Winarso, E. 2015. Prediksi Harga Emas Dunia sebagai Pendukung Keputusan Investasi Saham Emas Menggunakan Teknik Data Mining. KALBI Scientia Jurnal Sains dan Teknologi

Montgomery, D. C., Jennings, C. L. and Kulahci, M. 2008. Introduction to Time Series Analysis and Forecasting. New Jersey: John Wiley \& Sons

Pindyck, R. S. and Rubinfeld, D. L. 1998. Econometric Models and Economic Forecasts, $4^{\text {th }}$ Ed. Singapore: The McGraw-Hill

Ruppert, D. and Matteson D. S. 2011. Statistics and Data Analysis for Financial Engineering. New York: Springer

Trianto, D. W. 2015. Uji Kointegrasi dengan Metode Johansen dan Aplikasinya pada Data Harga Sembako di Pasar Induk Kota Yogyakarta [Tesis]. Yogyakarta: Universitas Negri Yogyakarta

Tripathy, N. 2017. Forecasting Gold Price with Auto Regressive Integrated Moving Average Model. International Journal of Economics and Financial Issue, 7(4), 324-329

Untari, N., Matjik, A. A. dan Saefuddin, A. 2009. Analisis Deret Waktu dengan Ragam Galat Heterogen dan Asimetri. Forum Statistika dan Komputasi, Vol. 14 No. 1 
Wei, W. W. S. 2006. Time Series Analysis: Univariate and Multivariate Methods. 2nd $E d$. Canada: Addison Wesley Publishing Company 